\title{
东非大裂谷埃塞俄比亚段内 $\mathrm{C}_{3}$ 植物叶片 $\delta^{13} \mathrm{C}$ 和 $\delta^{15} \mathrm{~N}$ 及其环境指示意义
}

\author{
刘晓宏 ${ }^{(1}$ 赵良菊 ${ }^{(2}$ Menassie Gasaw ${ }^{(3)}$ 高登义 ${ }^{(4}$ 秦大河 $^{(1}$ 任贾文 ${ }^{(1}$ \\ (1) 中国科学院寒区旱区环境与工程研究所冰冻圈与环境联合重点实验室, 兰州 730000; (2) 中国科学院寒区旱区环境与工程研究所 \\ 寒旱区流域水文及应用生态实验室, 兰州 730000; (3) Department of Biology, University of Addis Ababa, P. O. Box-62619, Addis Ababa, \\ Ethiopia; (4) 中国科学院大气物理研究所, 北京 100029. E-mail: liuxh@lzb.ac.cn
}

摘要 在中国科学探险协会的资助下, 对东非大裂谷埃塞俄比亚段内不同区域植物叶片稳定碳 $\left(\delta^{13} \mathrm{C}\right)$ 和氮 $\left(\delta^{15} \mathrm{~N}\right)$ 同位素比率进行了分析, 探讨了植物叶片 $\delta^{13} \mathrm{C}$ 和 $\delta^{15} \mathrm{~N}$ 的分布特征及其与环境要素之间的关 系. 结果表明在冷湿环境下 $\mathrm{C}_{3}$ 植物叶片 $\delta^{13} \mathrm{C}$ 的平均值为 $(-26.7 \pm 0.4) \%$; 温暖湿润环境下为 $(-29.7 \pm 0.6) \%$; 千热环境下为 $(-26.9 \pm 1.2) \%$. 植物叶片 $\delta^{15} \mathrm{~N}$ 的分布区间为 $(-1.4 \pm 1.7) \% 0 \sim(14.3 \pm 0.1) \%$ ，生 长在干燥炎热环境的植物表现为较高的 $\delta^{15} \mathrm{~N}$, 温暖湿润环境的 $\delta^{15} \mathrm{~N}$ 居中, 高海拔冷湿环境植物 $\delta^{15} \mathrm{~N}$ 最 小. 植物叶片 $\delta^{13} \mathrm{C}$ 和 $\delta^{15} \mathrm{~N}$ 之间的关系型可分为 3 类: 分别代表寒冷湿润、温暖湿润和干燥炎热的生长 环境, 反映了植物生长环境的异质性.

植物 $\delta^{15} \mathrm{~N}$ 与年均降雨量和海拔均为极显著负相关 $(P<0.001)$; 与年均温度显著正相关 $(P<0.01)$. 年降雨量每增加 $100 \mathrm{~mm}$, 海拔每增加 $1000 \mathrm{~m}$, 植物 $\delta^{15} \mathrm{~N}$ 分别偏负 $1.0 \%$ 和 $2.0 \%$; 年均温度每增加 $1^{\circ} \mathrm{C}$, $\delta^{15} \mathrm{~N}$ 平均值则偏正 $0.5 \%$. 降水和温度与氮同位素存在相关关系, 解释方差分别为 $53.6 \%$ 和 $31.8 \%$, 因此 降水和温度对 $\mathrm{C}_{3}$ 植物氮同位素分馏起主要作用. 植物 $\delta^{13} \mathrm{C}$ 与年均温度呈弱正相关关系, 但与年平均降 水和海拔的关系均表现为二次曲线型. 当降雨量低于 $1019.3 \mathrm{~mm}$, 海拔低于 $2400 \mathrm{~m}$ 时, $\delta^{13} \mathrm{C}$ 随降雨量和 海拔的增加而偏负, 而当降雨量与海拔高于此值时, $\delta^{13} \mathrm{C}$ 随二者的增加而偏正. 研究结果说明海拔变化 引起水热条件的改变对植物碳同位素分馏的影响存在一个转换点.

关键词 碳氮同位素 温度 降水 海拔 埃塞俄比亚东非大裂谷

碳和氮是植物组织的重要组成部分, 它们在植 物生理代谢过程中密切关联 ${ }^{1]}$. 植物组织的碳 $\left(\delta^{13} \mathrm{C}\right)$ 和氮 $\left(\delta^{15} \mathrm{~N}\right)$ 同位素比率在很大程度上受到生长环境 的影响, 因此可通过发掘沉积物中的古植物有机组 织来进行古环境的重建 ${ }^{[1,2]}$. 在对由沉积物得到的同 位素结果进行解释时, 都涉及到陆生植物碳氮同位 素组成的问题, 表明陆生植物同位素变化研究对正 确解释陆相沉积物的结果和提取可靠的古环境信息 具有十分重要意义. 哺乳动物组织的同位素比率由 底层食物链中植物组织的同位素组成所决定, 因此 植物组织 $\delta^{13} \mathrm{C}$ 和 $\delta^{15} \mathrm{~N}$ 比率广泛应用于古食性研究 ${ }^{[3,4]}$, 而且古食性分析的可靠性很大程度受制于对现代植物 $\delta^{13} \mathrm{C}$ 和 $\delta^{15} \mathrm{~N}$ 比率变化范围和类型的详细了解.

$\mathrm{C}_{3}$ 和 $\mathrm{C}_{4}$ 植物最显著的差异是固定 $\mathrm{CO}_{2}$ 的光合作
用途径不同, $\mathrm{C}_{3}$ 植物对 ${ }^{13} \mathrm{C}$ 的识别力高于 $\mathrm{C}_{4}$ 植物, 因 此 $\mathrm{C}_{3}$ 植物具有较低的 $\delta^{13} \mathrm{C}$ 值 ${ }^{[5,6]}$. 全球 $\mathrm{C}_{3}$ 植物的 $\delta^{13} \mathrm{C}$ 值的范围在 $-22.0 \%$ $-37.0 \%$ 之间，平均值在 $-27.0 \%$ 左右; $\mathrm{C}_{4}$ 植物 $\delta^{13} \mathrm{C}$ 值在 $-9.0 \%$ $-15.0 \%$ 之间, 平均值 在- $12.5 \%$ 左右 ${ }^{[5,6]} . \mathrm{C}_{3}$ 植物的 $\delta^{13} \mathrm{C}$ 值因受环境变化和 植物生理调节和响应的影响, 在个体、品种、群落之 间存在较大变幅 ${ }^{[5 \sim 7]}$. 植物组织中 $\delta^{15} \mathrm{~N}$ 同位素比率与 土壤的类型和有机物的 $\delta^{15} \mathrm{~N}$ 值、气候、氮同化和氮 有效性密切相关 ${ }^{[8 \sim 10]}$. 生物组织的 $\delta^{15} \mathrm{~N}$ 比率变化范 围在 $-10.0 \%$ $+20.0 \%$ 之间.

正因为植物组织 $\delta^{13} \mathrm{C}$ 和 $\delta^{15} \mathrm{~N}$ 在不同环境下存在 很大差异, 所以对古环境和古食性研究的准确重建 需要详细了解因环境不同而引起的植物同位素组成 的变化 ${ }^{[3,9,11]}$. 在自然生态系统中, 植物组织的 $\delta^{13} \mathrm{C}$ 和

2006-07-28 收稿, 2006-09-20 接受

中国科学院寒区旱区环境与工程研究所引进人才基金(批准号: 2005104)、国家自然科学基金(批准号: 40501076)、中国科学探险协会《中 国科学探险》杂志社和中国科学院创新团队国际合作伙伴计划(批准号: CXTD-Z2005-2)资助 
$\delta^{15} \mathrm{~N}$ 在不同环境条件下发生变化, 且两者在植物种 内和种间均存在显著差异 ${ }^{[1,12 \sim 17]}$. 近年来，尽管对热 带一些地区的植物种类和生长环境对植物 $\delta^{13} \mathrm{C}$ 和 $\delta^{15} \mathrm{~N}$ 的种间差异及其对生长环境响应方面的研究有 了新进展 ${ }^{[3,11,16,17]}$, 但人们对植物种类和环境引起的 同位素组成变化及其指示的生态意义的了解并不完 全清楚 ${ }^{[18,19]}$

在东非大裂谷埃塞俄比亚境内, 广泛分布着大量 的湖泊和河流，该区域有“东非水塔”之称. 随着海拔 (900 4000 m)和地理环境的变化, 分布着从干旱灌丛到 高山草甸等不同的植被类型. 该区域独特的地理条件 使得依环境梯度的变化来研究植物 $\delta^{15} \mathrm{~N}$ 和 $\delta^{13} \mathrm{C}$ 组成对 气候环境的响应成为可能. 研究表明, 东非大裂谷湖泊 沉积中地表有机物的唯一来源是植物残体，通过沉积 物中叶片残留物的分析，可建立长达千年连续的同位 素序列古环境记录 ${ }^{[2]}$. 因此, 本研究通过对东非大裂谷 埃塞俄比亚境内现生植物叶片 $\delta^{15} \mathrm{~N}$ 和 $\delta^{13} \mathrm{C}$ 的分布特征 进行系统分析, 旨在了解环境条件(温度、降水和海拔) 对植物碳氮同位素分馏的影响及其之间的关系，同时 为区域古环境和古食性研究提供科学依据.

\section{1 研究区域概况}

东非大裂谷是地球上最大的裂谷系统, 被称为 地球上最大的“伤疮”. 整个裂谷系统分为东支和西 支. 东支从阿法(Afar)地区开始, 经过埃塞俄比亚和 肯尼亚裂谷, 到达坦桑尼亚北部结束, 长达 2200 $\mathrm{km}^{[20]}$. 其中埃塞俄比亚裂谷约 $50 \mathrm{~km}$ 宽, $330 \mathrm{~km}$ 长, 海拔从 750 到 $4000 \mathrm{~m}^{[20]}$. 采样点主要分布在埃塞俄 比亚裂谷内(图 1).

本研究区域包括低海拔的干旱稀疏草原(Sof Omar Cave (SO)和 Awash National Park (AW))、温暖 湿润的针阔混交林 (Chencha Mt. (CH) 和 Wendo Genet (WE))、较高海拔区(Bale National Park (BA))及高海 拔地区的高山草甸(Sanettie Plateau (SA)). 其中 SO

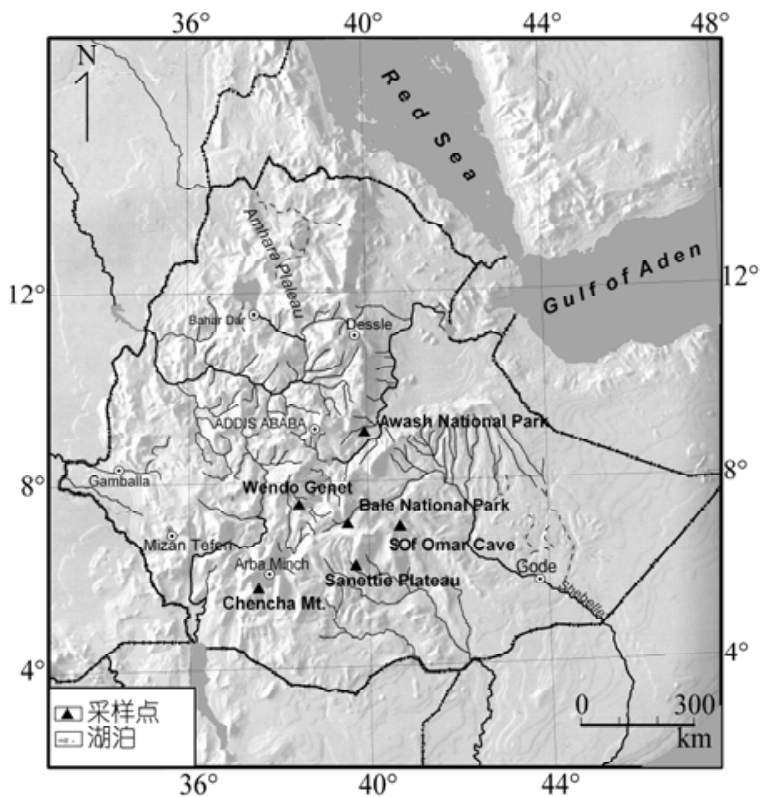

图 1 东非大裂谷埃塞俄比亚段内样点分布图

和 $\mathrm{AW}$ 的气候特征为干旱少雨, 温度较高蒸发量较大. $\mathrm{SA}$ 气候特征为低温、高降水和低蒸发. $\mathrm{CH}$ 和 WE 及 BA 三个地区的降水接近，但 BA 因海拔较高导致温 度较低. 该区域表层土壤主要由火山沉积物发育而 来，有肥沃的砂土和草甸土等 ${ }^{[21]}$.

因埃塞俄比亚国的气象记录并不完整且观测站点 较少, 因此在本研究中选择了距离采样点最近的气象 站点多年平均站点的资料代表采样点气候条件(表 1).

\section{2 样品采集及分析}

在中国科学探险协会《中国科学探险》杂志的资 助下, 2005 年 8 月笔者在东非大裂谷埃塞俄比亚境内 进行了科学考察. 在东非大裂谷埃塞俄比亚段(图 1) 选择 6 个不同区域，对地表植物进行了系统取样，共 采集 26 种优势植物的成熟叶片(见图 1 和表 1). 为避 免光照、叶片成熟度 ${ }^{[27]}$ 及人为干扰等因素的影响, 选 择朝阳、生长状况一致和无人工干扰的区域进行样品

表 1 埃塞俄比亚东非大裂谷样点地理特征及气候条件

\begin{tabular}{|c|c|c|c|c|c|c|c|}
\hline 样点/缩略名 & 经度 & 纬度 & 海拔 $/ \mathrm{m}$ & 温度 $/{ }^{\circ} \mathrm{C}$ & 降水 $/ \mathrm{mm}$ & 气候类型 & 气象资料来源 \\
\hline Mt. Chencha/CH & $37^{\circ} 34.66^{\prime} \mathrm{E}$ & $06^{\circ} 9.13^{\prime} \mathrm{N}$ & 1850 & $14.0^{\mathrm{b})}$ & 1017 & 温暖湿润 & Eshetu 等 ${ }^{[22]}$ \\
\hline Wendo Genet/WE & $38^{\circ} 38.39^{\prime} \mathrm{E}$ & $07^{\circ} 4.69^{\prime} \mathrm{N}$ & 1950 & 19.5 & 1240 & 温暖湿润 & Teklay 等 ${ }^{[23]}$ \\
\hline Sof Omar Cave/SO & $40^{\circ} 50.80^{\prime} \mathrm{E}$ & $06^{\circ} 54.36^{\prime} \mathrm{N}$ & 1260 & 20.4 & 716 & 炎热干燥 & Lemenih 等[24] \\
\hline Sanettie Plateau/SA & $39^{\circ} 50.53^{\prime} \mathrm{E}$ & $06^{\circ} 48.51^{\prime} \mathrm{N}$ & 4050 & 13.6 & 1370 & 寒冷湿润 & Lemenih 等 ${ }^{[24]}$ \\
\hline Bale National Park/BA ${ }^{a)}$ & $39^{\circ} 47.40^{\prime} \mathrm{E}$ & $07^{\circ} 5.75^{\prime} \mathrm{N}$ & 3200 & 14.9 & 1175 & 温暖湿润 & Anon 等 ${ }^{[25]}$ \\
\hline Awash National Park/AW & $40^{\circ} 0.72^{\prime} \mathrm{E}$ & $08^{\circ} 50.6^{\prime} \mathrm{N}$ & 930 & 25.05 & $550 \sim 620$ & 炎热干燥 & Abule 等 ${ }^{[26]}$ \\
\hline
\end{tabular}

a) Bale National Park 的环境条件与 Dessie 点相近，选择该点气象资料代表 Bale National Park 的气候资料 ${ }^{[25]}$. b) 气象数据引自 West Chench 山脉 ${ }^{[23]}$, 海拔与本研究样点存在一定差异 $(530 \mathrm{~m})$, 但在本研究中仍运用该值进行分析 
采集. 考虑到植物个体之间的差异 ${ }^{[28]}$, 取样时选择 3 4 株冠幅和株高相似的植株, 随机采集 6 16 片叶 片作为一个样品, 每个样品重复 2 次. 所有样品在野 外初步风干后带回实验室.

在实验室内, 用蒸馏水对样品超声清洗后在 $60^{\circ} \mathrm{C}$ 下烘干 $48 \mathrm{~h}$, 使样品完全干燥 ${ }^{[29,30]}$. 用研磨机(p-23, Fritsch Company, Germany)进行研磨, 使样品均一化. 在中国科学院地质与地球物理研究所稳定同位素分 析实验室, 植物叶片 $\delta^{13} \mathrm{C}$ 和 $\delta^{15} \mathrm{~N}$ 用元素分析仪(Flash EA 1112)转化后在 MAT-253 质谱仪上进行测试. 样品 $\delta^{13} \mathrm{C}$ 和 $\delta{ }^{15} \mathrm{~N}$ 同位素比率重复测定误差分别小于 $0.1 \%$ 和 $0.2 \%$. $\delta^{13} \mathrm{C}$ 和 $\delta^{15} \mathrm{~N}$ 分别转换为相对于国际标准的 Vienna Peedee belemnite (V-PDB) 和大气氮 (Atmospheric $\mathrm{N}_{2}$ ) 的 $\delta$ 值报道.

\section{3 结果分析}

\section{1 植物叶片 $\delta^{15} \mathrm{~N}$ 和 $\delta^{13} \mathrm{C}$ 频率分布}

在东非大裂谷埃塞俄比亚段 6 个不同区域内, 植 物叶片的 $\delta^{15} \mathrm{~N}$ 和 $\delta^{13} \mathrm{C}$ 因环境条件的不同表现出显著 差异(表 2 和图 2). 植物 $\delta^{15} \mathrm{~N}$ 的分布区间在 $-1.4 \% 0$ 和 $14.2 \%$ 之间 (表 2), 其中 $73.5 \%$ 的数据分布在 $0.0 \sim 8.0 \%$ 之间， $14.0 \%$ 的数据分布在 $-2.0 \% \sim 0.0$ 之间， 分布在 $9.0 \%$ $15.0 \%$ 之间的植物占 $12.0 \%$ (图 2), 表明 $\delta^{15} \mathrm{~N}$ 因植物种类和生长环境的不同存在较大变率. $\delta^{15} \mathrm{~N}$ 均值在 SO 地区最高 $(8.4 \% 0 \pm 1.5 \%$ ), 在 SA 区域 最低 $(0.1 \% 0 \pm 1.4 \%$ ).

除一种植物(Eophorbia fertun)属于 $\mathrm{C}_{4}$ 或景天植 物 $(\mathrm{CAM})\left(\delta^{13} \mathrm{C}:-15.9 \% 0 \pm 0.1 \% 0\right)$ 外, 其余植物均为 $\mathrm{C}_{3}$ 植物，其叶片 $\delta{ }^{13} \mathrm{C}$ 的分布区间为 $-25.1 \%$ - $31.3 \%$, 位于 O'Leary 所报道的 $\mathrm{C}_{3}$ 植物的 $\delta^{13} \mathrm{C}$ 在-34.0\% $-22.0 \%$ 之间的范围内. $\mathrm{C}_{3}$ 植物的 $\delta^{13} \mathrm{C}$ 呈单峰分布(图 2 ), 平均值为 $-28.0 \%$. 该平均值比在中国北方测定的 461 种 $\mathrm{C}_{3}$ 植物样品碳同位素的平均值 $(-27.1 \%$ ) 偏 负 ${ }^{[31]}$. 鉴于本研究所涉及的 26 种优势植物中只有一 种为 $\mathrm{C}_{4}$ 或景天植物 $(\mathrm{CAM})$, 故在植物同位素组成与 环境关系研究中, 仅讨论环境和气候条件对 $\mathrm{C}_{3}$ 植物 的 $\delta^{15} \mathrm{~N}$ 和 $\delta^{13} \mathrm{C}$ 的影响.

\section{2 植物叶片 $\delta^{15} \mathrm{~N}$ 和 $\delta^{13} \mathrm{C}$ 的区域平均}

东非大裂谷埃塞俄比亚段 $\mathrm{C}_{3}$ 植物叶片 $\delta^{15} \mathrm{~N}$ 和 $\delta^{13} \mathrm{C}$ 的平均值分布及两者关系型见图 3. 植物的两种 同位素分布可分为 3 种类型. 在 $\mathrm{SO}$ 和 $\mathrm{AW}$, 植物的 $\delta^{15} \mathrm{~N}$ 较高 $((7.6 \pm 0.7) \% \sim(8.0 \pm 1.5) \% 0)$, 反映了生长在干
表 2 东非大裂谷埃塞俄比亚段植物叶片 $\delta{ }^{15} \mathrm{~N}$ 和 $\delta{ }^{13} \mathrm{C}$ 同位素组成 ${ }^{\text {a) }}$

\begin{tabular}{|c|c|c|c|}
\hline 样点 & 植物种类 & $\delta{ }^{15} \mathrm{~N} \pm \mathrm{SE} / \%$ & $\delta^{13} \mathrm{C} \pm \mathrm{SE} / \% 0$ \\
\hline \multirow{7}{*}{$\mathrm{CH}$} & Ficus sylomorous & $3.2 \pm 0.2$ & $-29.5 \pm 0.1$ \\
\hline & Comiliane sp. & $3.9 \pm 0.3$ & $-29.6 \pm 1.1$ \\
\hline & Senecio sp. & $4.3 \pm 0.3$ & $-31.3 \pm 0.1$ \\
\hline & Justicia sp. & $5.7 \pm 0.4$ & $-28.5 \pm 0.2$ \\
\hline & Solanum sp. & $4.2 \pm 0.7$ & $-29.0 \pm 0.1$ \\
\hline & Leucas & $3.0 \pm 1.3$ & $-30.6 \pm 1.9$ \\
\hline & 区域平均 & $4.1 \pm 0.4$ & $-29.8 \pm 0.4$ \\
\hline \multirow{6}{*}{ WE } & Justicia sp. & $3.8 \pm 0.7$ & $-30.4 \pm 0.1$ \\
\hline & Carissa edulis & $-1.1 \pm 0.1$ & $-29.9 \pm 0.3$ \\
\hline & Solanum sp. & $6.9 \pm 1.0$ & $-28.5 \pm 0.1$ \\
\hline & Ficus sylomorous & $4.7 \pm 1.7$ & $-29.3 \pm 0.8$ \\
\hline & Juniperus procera & $-0.2 \pm 0.7$ & $-28.2 \pm 0.1$ \\
\hline & 区域平均 & $2.8 \pm 1.5$ & $-29.3 \pm 0.4$ \\
\hline \multirow{9}{*}{$\mathrm{SO}$} & Terminalia brownii & $3.6 \pm 0.1$ & $-27.0 \pm 0.4$ \\
\hline & Eoeiphur antichrhrist & $14.2 \pm 0.1$ & $-26.3 \pm 1.1$ \\
\hline & Justicia sp. & $7.4 \pm 1.5$ & $-26.4 \pm 0.5$ \\
\hline & Dubera sp. & $5.3 \pm 0.1$ & $-29.9 \pm 0.6$ \\
\hline & Mytens seneydensis & $5.5 \pm 0.9$ & $-26.4 \pm 0.3$ \\
\hline & Solanum sp. & $10.0 \pm 0.7$ & $-26.2 \pm 1.9$ \\
\hline & Cadeba sp. & $12.5 \pm 1.1$ & $-25.1 \pm 0.4$ \\
\hline & Eophorbia fertun & $7.6 \pm 0.6$ & $-15.9 \pm 0.1$ \\
\hline & 区域平均 ～ & $8.4 \pm 1.5$ & $-27.0 \pm 0.6$ \\
\hline \multirow{5}{*}{ SA } & Alechemella haunaii & $-1.3 \pm 0.7$ & $-26.1 \pm 0.3$ \\
\hline & Europes prostratus & $4.2 \pm 0.1$ & $-28.0 \pm 0.1$ \\
\hline & Hebenstretia dentate & $-1.3 \pm 1.0$ & $-27.7 \pm 0.1$ \\
\hline & Helichrysum splendidum & $-1.4 \pm 1.7$ & $-25.1 \pm 0.4$ \\
\hline & 区域平均 & $0.1 \pm 1.4$ & $-26.7 \pm 0.7$ \\
\hline \multirow{8}{*}{ BA } & Euphorbia dumalis & $4.4 \pm 0.1$ & $-26.7 \pm 0.2$ \\
\hline & Juniperus procera & $1.3 \pm 0.9$ & $-27.1 \pm 0.1$ \\
\hline & Kniphofia foliosa & $4.2 \pm 0.4$ & $-27.6 \pm 1.1$ \\
\hline & Satarie sp. & $1.2 \pm 0.7$ & $-29.3 \pm 0.1$ \\
\hline & Cynoglossum sp. & $3.9 \pm 0.7$ & $-29.7 \pm 0.2$ \\
\hline & Hypericum revoultum & $2.1 \pm 0.1$ & $-28.5 \pm 0.6$ \\
\hline & Carduus chamaecephallus & $3.4 \pm 0.7$ & $-27.6 \pm 0.3$ \\
\hline & 区域平均 ～～～～～～～ & $2.9 \pm 0.5$ & $-28.1 \pm 0.4$ \\
\hline \multirow{5}{*}{ AW } & Grewia sp. & $9.4 \pm 0.1$ & $-26.8 \pm 2.0$ \\
\hline & Dubera sp. & $6.4 \pm 0.1$ & $-25.9 \pm 0.4$ \\
\hline & Comeliana sp. & $6.8 \pm 0.1$ & $-27.5 \pm 0.1$ \\
\hline & Crotalaria sp. & $7.6 \pm 0.7$ & $-28.3 \pm 0.3$ \\
\hline & 区域平均 & $7.6 \pm 0.7$ & $-27.1 \pm 0.5$ \\
\hline
\end{tabular}

a) 样点名以表 1 缩略名代替. 表中 SE 代表平行采样的样品同 位素值误差. 表中 Eophorbia fertun 属 $\mathrm{C}_{4}$ 或景天类植物, 在 $\mathrm{SO}$ 区域同 位素平均值未包含其值

燥炎热环境植物的氮同位素分布型; BA, WE 和 $\mathrm{CH}$ 三个区域的 $\delta^{15} \mathrm{~N}$ 为一组，其范围在 $(2.8 \pm 1.5) \%$ $(4.1 \pm 0.4) \%$ 之间，反映了温暖湿润环境植物的氮同位 素分布型; 高海拔冷湿环境的植物 (SA) $\delta^{15} \mathrm{~N}$ 最小 $((0.1 \pm 1.4) \% 0)$. 对植物叶片 $\delta^{13} \mathrm{C}$ 而言, 与高海拔的 SA 和炎热干旱的 $\mathrm{AW}$ 和 SO 区域相比, 在温暖湿润的 BA, $\mathrm{WE}$ 和 $\mathrm{CH}$ 区域, 植物的 $\delta^{13} \mathrm{C}$ 显著偏负. 


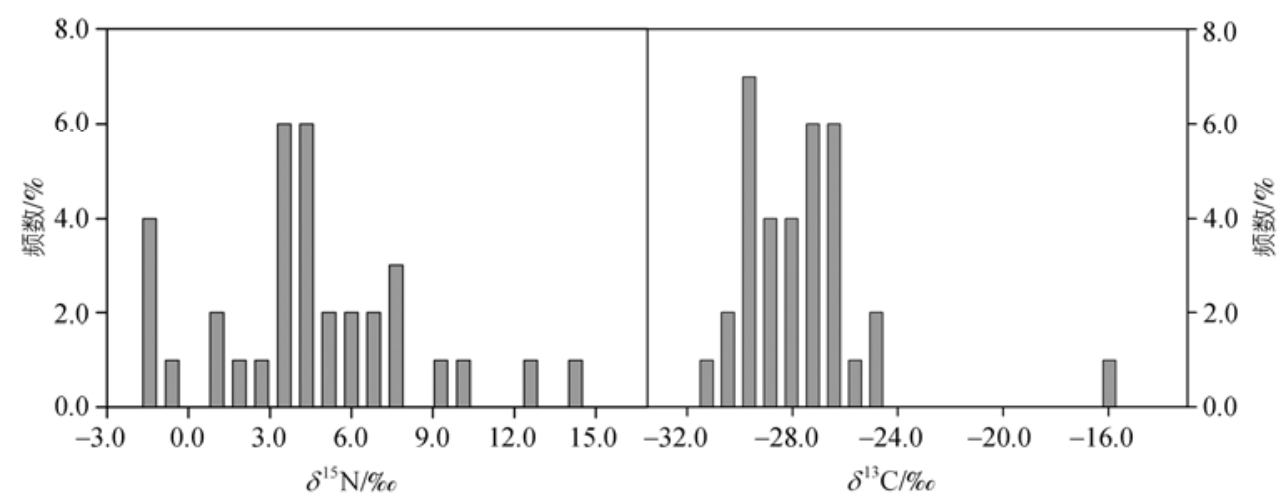

图 2 叶片 $\delta^{15} \mathrm{~N}$ 和 $\delta^{13} \mathrm{C}$ 频率分布直方图

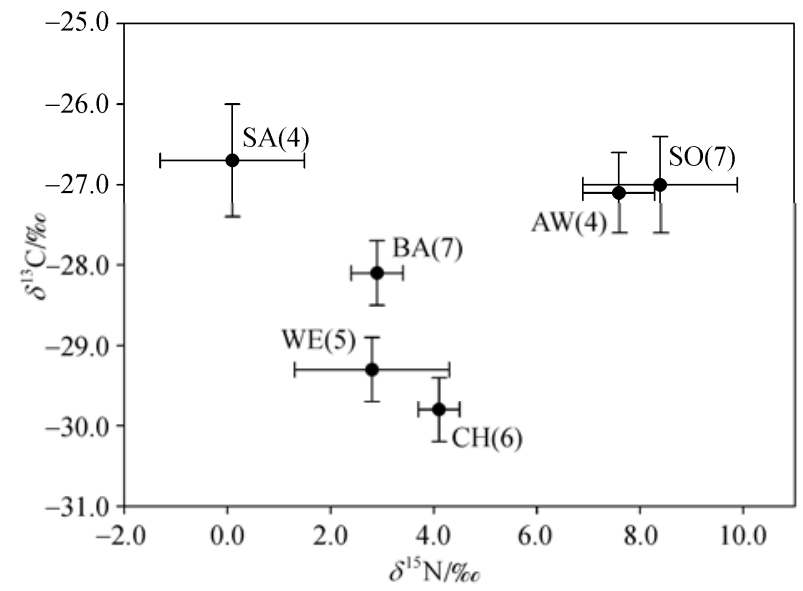

图 3 植物叶片 $\delta^{15} \mathrm{~N}$ 和 $\delta^{13} \mathrm{C}$ 的区域平均 样点括号的数字代表样点植物种类数

3.3 植物叶片 $\delta^{15} \mathrm{~N}$ 和 $\delta^{13} \mathrm{C}$ 与环境要素关系

植物叶片 $\delta^{15} \mathrm{~N}$ 和 $\delta^{13} \mathrm{C}$ 与年均温度、年均降雨量 及海拔的关系见图 4. 植物叶片 $\delta^{15} \mathrm{~N}$ 与年均温度极显 著正相关 $(P<0.001)$, 年均温度每增加 $1^{\circ} \mathrm{C}$, 植物叶 片 $\delta^{15} \mathrm{~N}$ 偏正 $0.5 \%$ (图 4). 植物叶片 $\delta^{15} \mathrm{~N}$ 与年均降雨 量和海拔均为极显著负相关, 其中降雨量每增加 100 $\mathrm{mm}, \delta^{15} \mathrm{~N}$ 偏负 $1.0 \%$; 海拔每增加 $1000 \mathrm{~m}, \delta^{15} \mathrm{~N}$ 偏负 $2.0 \%$. 除与年均温度呈弱的正相关关系外 $(P=0.112)$, 植物叶片 $\delta^{13} \mathrm{C}$ 与年均降雨量和海拔的关系均为二次 曲线，且回归方程均达极显著水平 $(P<0.001)$ (图 4). 植物叶片 $\delta^{13} \mathrm{C}$ 达到最小值时所对应的降雨量和海拔 分别为 1019.2 和 $2400 \mathrm{~m}$. 当降雨量和海拔分别低于 1019.2 和 $2400 \mathrm{~m}$ 时, 植物叶片 $\delta^{13} \mathrm{C}$ 值随降雨量和海 拔的增加而偏负; 当二者分别高于 1019.2 和 $2400 \mathrm{~m}$ 时, $\delta^{13} \mathrm{C}$ 随二者的增加而偏正.
4 讨论

\section{1 环境因子对碳氮同位素分馏的影响}

环境条件对植物 $\delta^{13} \mathrm{C}$ 产生显著影响, 其中温度、 降水、相对湿度和大气 $\mathrm{CO}_{2}$ 浓度等均是影响植物碳同 位素分馏的重要因素. 据 Farquhar 等 ${ }^{[7]}$ 对 $\mathrm{C}_{3}$ 植物碳同 位素分馏机理的阐述, 较低的气孔导度或较高的光 合速率或两个因素的综合作用均使细胞内 $\mathrm{CO}_{2}$ 浓度 降低，在这种条件下合成的植物组织具有较高的 $\delta^{13} \mathrm{C}$. 本研究区域远离工业区及人类居住区，故不考 虑大气 $\mathrm{CO}_{2}$ 浓度及其 $\delta^{13} \mathrm{C}$ 对植物碳同位素分馏的影 响. 本研究结果显示温度和 $\delta^{13} \mathrm{C}$ 值之间存在弱的正 相关关系, 说明温度对植物碳同位素分馏有一定影 响, 但非控制因子 ${ }^{[29]}$. 也有结果表明植物 $\delta^{13} \mathrm{C}$ 与温 度呈负相关关系 ${ }^{[29,32]}$. 植物 $\delta^{13} \mathrm{C}$ 与温度或正或负关 系的存在与植物生长季温度高于或低于植物生长的 最适温度密切相关 ${ }^{[28]}$.

降雨量和海拔与植物叶片 $\delta^{13} \mathrm{C}$ 的关系均符合二 次曲线(图 4), 说明二者对碳同位素分馏的影响存在 一致性. 在中国北方, 年降水量低于 $700 \mathrm{~mm}$ 时, $\mathrm{C}_{3}$ 植物 $\delta^{13} \mathrm{C}$ 与降水量变化也表现为负相关关系 ${ }^{[31]}$. 在 南非降水变化范围 200 1300 $\mathrm{mm}$ 的地区, $\mathrm{C}_{3}$ 植被的 $\delta^{13} \mathrm{C}$ 与年均降水呈显著负相关关系 ${ }^{[30]}$. 在本研究中, 降水量在 550 1400 mm 之间变化(表 1). 当降水量小 于 $1019.2 \mathrm{~mm}$ 时, 降水量和植物 $\delta^{13} \mathrm{C}$ 呈现出与南 非 ${ }^{[30]}$ 和中国北方 ${ }^{[31]}$ 一致的负相关关系; 当降水量超 过 $1019.2 \mathrm{~mm}$ 时, $\mathrm{C}_{3}$ 植物 $\delta^{13} \mathrm{C}$ 值与降水的关系表现为 正相关关系. Guo 等 ${ }^{[33]}$ 研究发现青藏高原北部植物 $\delta{ }^{13} \mathrm{C}$ 与降水量为正相关关系，而在高原南部为负相 

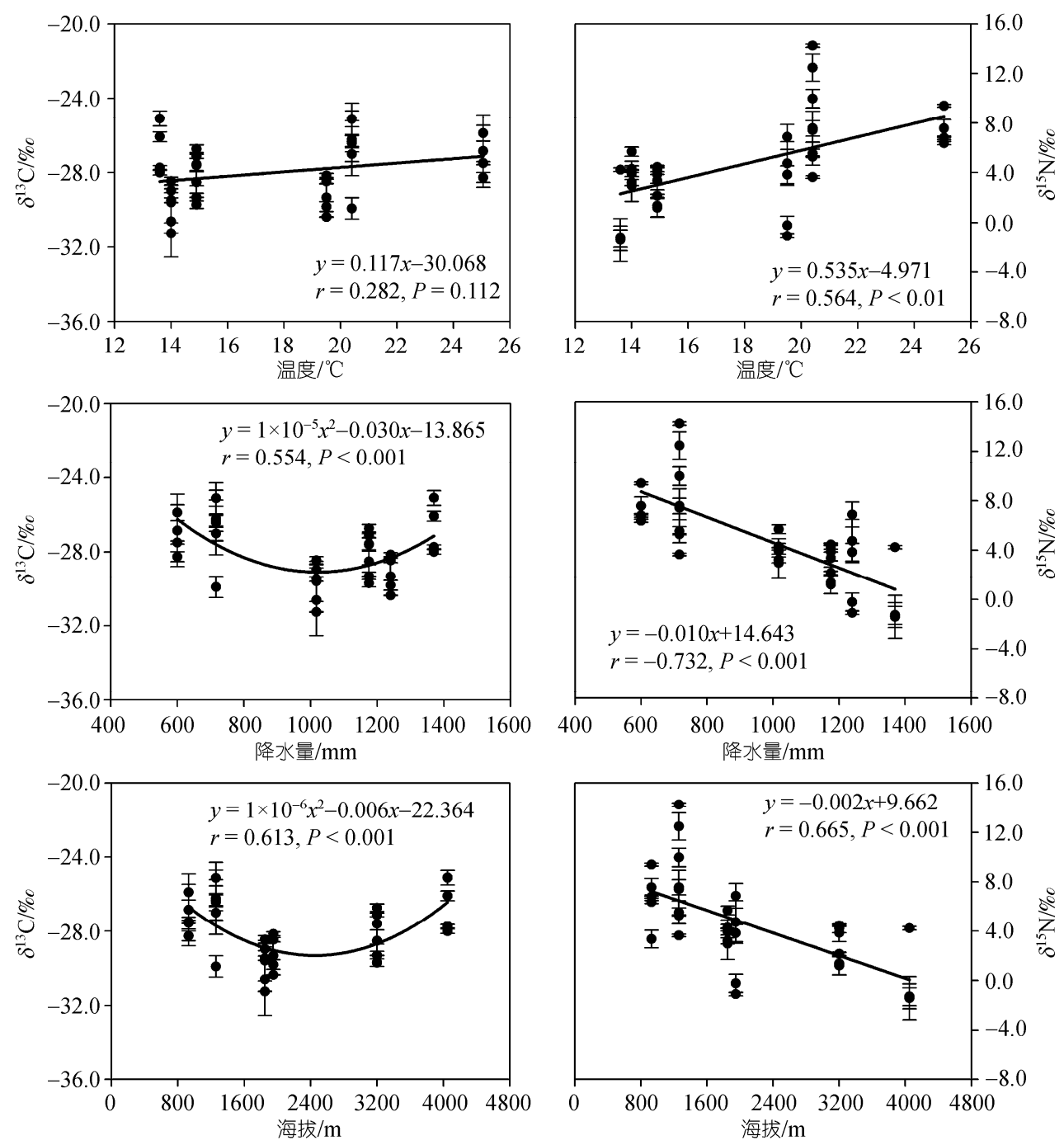

图 4 植物叶片 $\delta^{15} \mathrm{~N}$ 和 $\delta^{13} \mathrm{C}$ 比率与温度、降水量和海拔的关系

关关系, 表明植物 $\delta^{13} \mathrm{C}$ 与降水之间的关系会因地理 环境的变化而改变.

Qiang 等 ${ }^{\left[{ }^{[4]}\right.}$ 的研究表明, 以海拔 $3000 \mathrm{~m}$ 为界, 在 高于和低于此界限时青海云杉针叶气孔密度和叶片 $\delta^{13} \mathrm{C}$ 随海拔高度变化表现出不同的变化趋势. 旺罗 等 ${ }^{[35]}$ 研究表明, 在海拔 $3400 \mathrm{~m}$ 以上, 青藏高原植物 的 $\delta^{13} \mathrm{C}$ 海拔的升高而偏正. 本研究表明在 800 4000 m 海拔范围内, 当海拔低于 $2400 \mathrm{~mm}$ 时植物叶片 $\delta^{13} \mathrm{C}$ 随海拔的增加而偏负, 而高于此值时则随海拔的增 加而偏正(图 4). 说明在海拔低于 $2400 \mathrm{~m}$ 时, 水分是 植物碳同位素分馏的控制因子，而当海拔高于 2400 $\mathrm{m}$ 时, 随温度的逐步降低和降水量的增加 ${ }^{[36]}$, 温度对 碳同位素分馏的控制作用加强，成为碳同位素分馏
的限制因子. 但在北半球，海拔在 72 2130 $\mathrm{m}$ 的范围 内常绿落叶松叶片碳同位素分辨率 $(\Delta)$ 与海拔表现出 一致的负相关关系 ${ }^{[37]}$. Sparks 等 ${ }^{[38]}$ 也得出相同的结果, 即河岸林植物叶片碳同位素分辨率 $(\Delta)$ 与海拔 $(600 \sim 2670 \mathrm{~m})$ 表现为一致的负相关关系, 即与 $\delta^{13} \mathrm{C}$ 为正相关关系. 鉴于植物 $\delta^{13} \mathrm{C}$ 与环境条件的复杂关 系, 在调查植被 $\delta^{13} \mathrm{C}$ 与环境因子的关系时, 应尽可 能的考虑到多个因素的综合作用对碳同位素分馏的 影响, 从而保证利用陆相沉积同位素进行古环境重 建的可靠性. 同时, 在有“东非水塔”之称的埃塞俄比 亚裂谷地区，有众多河流和湖泊，存在多种生态系统， 海拔变化较大, 与中国西北, 尤其青藏高原存在许多 类似的地方, 因此该区域的研究结果可以为我们在 
青藏高原的研究提供参考.

植物所吸收的氮同位素的种类和数量不但与其 生长的土壤条件如土壤类型、成土过程、土壤水分和 养分状况、细菌活性、 $\mathrm{pH}$ 值及温度等有关 ${ }^{[1,22,39]}$, 而 且与气候环境变化所引起的植物生理代谢过程的改 变密切相关 ${ }^{11}$. 不同地区土壤氮库中, 植物可吸收氮 含量的差异对植物组织 $\delta^{15} \mathrm{~N}$ 的影响不容忽视 ${ }^{[1]}$. 土 壤温度增加使得土壤 $\mathrm{NO}$ 气体通量增大 ${ }^{[39]}$, 导致土壤 富集 ${ }^{15} \mathrm{~N}$, 从而影响植物氮同位素组成. 当土壤湿度 过大时, 土壤呼吸速率剧减 ${ }^{[40]} \cdot \mathrm{C}_{3}$ 植物 $\delta^{15} \mathrm{~N}$ 与降水 量和海拔之间的负相关关系说明随降水量和海拔增 加植物叶片 $\delta^{15} \mathrm{~N}$ 偏负, 其原因可能与在冷湿环境下 土壤呼吸速率降低引起土壤中轻同位素 ${ }^{14} \mathrm{~N}$ 富集有 关 ${ }^{[39,41]}$. 在南非, 与湿润环境相比, 干旱环境的土壤 和植物均富集 ${ }^{15} \mathrm{~N}$, 即干旱环境的土壤和植物具有较 高的 $\delta^{15} \mathrm{~N}^{[39]}$. SA 地区海拔较高, 降雨量多但温度较 低, 相对于干旱环境生长植物表现为贫 ${ }^{15} \mathrm{~N}\left(\right.$ 低 $\delta^{15} \mathrm{~N}$ 值 $)^{[39]}$. 在 BA 国家公园、WE 雨林和 $\mathrm{CH}$ 山区, 气候 为温暖湿润型, 上述区域植物叶片的 $\delta^{15} \mathrm{~N}$ 比冷湿的 高原地区的高, 说明影响该区域土壤 $\delta^{15} \mathrm{~N}$ 的主要因 子为温度, 即随温度增加土壤 $\mathrm{NO}$ 等气体的释放增 加 ${ }^{[39]}$, 导致土壤富集 ${ }^{15} \mathrm{~N}$, 从而影响植物组织 $\delta^{15} \mathrm{~N}$. $\mathrm{SO}$ 和 $\mathrm{AW}$ 两个区域周围有河流分布, 气候炎热且降 水较少, 植物 $\delta^{15} \mathrm{~N}$ 较高, 与在南非和坦桑尼亚在海 岸和海盐较高区域的研究结果一致 ${ }^{[9,40]}$. 以往研究表 明水中氮富集 ${ }^{15} \mathrm{~N}$, 在河流边生长的植物对 $\mathrm{N}$ 的吸收 会受到通过河流水雾中 ${ }^{15} \mathrm{~N}$ 含量的影响 ${ }^{[42,43]}$. 这也可 能是两个区域植物 $\delta^{15} \mathrm{~N}$ 较高的原因之一(表 2).

\section{2 非洲 $\mathrm{C}_{3}$ 植被碳、氮同位素比率的空间比较}

在干旱、半沙漠及雨林区, 许多学者利用地表植 被稳定同位素的空间变化来研究全球变化对生态系 统的影响做了大量研究 ${ }^{[1,36,37,39]}$. 前人的研究 ${ }^{[9,30]}$ 及 本研究表明, 非洲不同地区 $\mathrm{C}_{3}$ 植被碳、氮同位素关 系型因地理位置和环境条件而异(图 5). 在肯尼亚, 植物组织的 $\delta^{15} \mathrm{~N}$ 平均值为 $(9.6 \pm 2.3) \%$ ，显著高于坦 桑尼亚、埃塞俄比亚和南非植物的 $\delta^{15} \mathrm{~N}$. 南非 ${ }^{[30,39]}$ 、 坦桑尼亚 ${ }^{[9]}$ 及埃塞俄比亚 $\mathrm{C}_{3}$ 植物叶片 $\delta^{15} \mathrm{~N}$ 变化范围 分别在 $(3.7 \pm 2.6) \% 0,(4.9 \pm 2.6) \%$ 及 $(4.5 \pm 3.7) \%$ 之间, 即 南非及坦桑尼亚植被 $\delta^{15} \mathrm{~N}$ 的变化范围完全处于埃塞 俄比亚裂谷段植被 $\delta^{15} \mathrm{~N}$ 的变化范围内. 在非洲植物 组织 $\delta^{15} \mathrm{~N}$ 主要受环境条件影响 ${ }^{[30,39]}$, 表明埃塞俄比
亚境内东非大裂谷植物生长环境的多样性 ${ }^{[42]}$. 而且 $\delta^{15} \mathrm{~N}$ 与年降水量显著负相关关系 ${ }^{[30,39]}$, 其中降水的 解释方差超过 $50 \%$ ，表明非洲 $\mathrm{C}_{3}$ 植物 $\delta^{15} \mathrm{~N}$ 分布型主 要受水分有效性控制. 引起非洲不同地区植被除了 温度、降水等气候要素的影响外，也与土壤类型等密 切相关 ${ }^{[11,42,44]}$. 土壤中有机质含量、细菌活性及黍粒 矿物含量等均影响植物对氮同位素组成的吸收. 如 在干旱或沙地环境, 土壤中富集 ${ }^{15} \mathrm{~N}$, 因而植物组织 的 $\delta^{15} \mathrm{~N}$ 较高 ${ }^{[39]}$; 然而在湿润环境土壤中贫 ${ }^{15} \mathrm{~N}$ ，因而 植物组织中 $\delta^{15} \mathrm{~N}$ 较低 ${ }^{[39,41]}$. 同时, 地理位置不同也 会导致植物氮同位素出现较大差异, 如在距离海岸 线近及盐生环境下生长的植物会富集 ${ }^{15} \mathrm{~N}^{[3]}$; 生长在 水边的植物氮同位素组成会受到水中有机氮同位素 组成的影响 ${ }^{[44]}$. 非洲不同区域现生植物 $\delta^{15} \mathrm{~N}$ 的分布 类型有助于我们对陆相沉积同位素记录的可靠、合理 的解释.

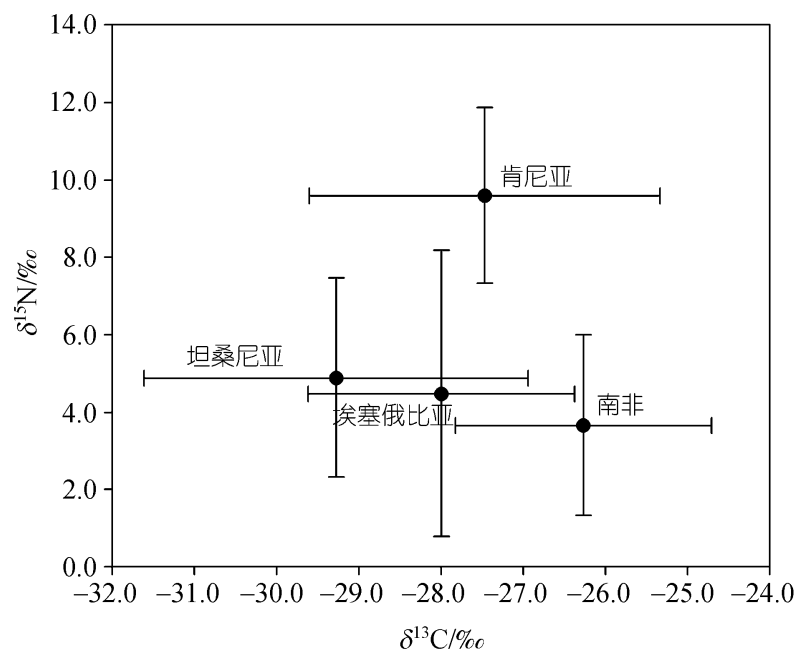

图 5 非洲不同地区 $\mathrm{C}_{3}$ 植被 $\delta^{13} \mathrm{C}$ 和 $\delta^{15} \mathrm{~N}$ 值之间关系型 南非 $\mathrm{C}_{3}$ 植被同位素值引自文献[30]; 肯尼亚和坦桑尼亚植物同位素数 据引自文献[9]. 误差棒表明区域所有样品的同位素值变化范围

植物组织 $\delta^{13} \mathrm{C}$ 的变化不仅与气候条件如水 分 ${ }^{[7,45]}$ 、温度 ${ }^{[29,32,46]}$ 等有关, 而且与地理位置 ${ }^{[11,36,37,39]}$ 如地貌和海拔及土壤条件如土壤类型和养分 ${ }^{[38,47]}$ 等 有关. 水分胁迫使得植物富集 ${ }^{13} \mathrm{C}^{[7]}$, 温度变化对碳

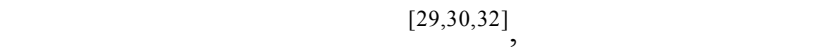
型也会对 $\delta^{13} \mathrm{C}$ 分馏造成影响 ${ }^{[28,47]}$. 南非降水与 $\mathrm{C}_{3}$ 植 物 $\delta^{13} \mathrm{C}$ 的负相关关系表明在干旱的非洲，水分是控 制碳同位素分馏的主要因子 ${ }^{[30]}$. 在东非大裂谷埃塞 俄比亚境内, 当降水量小于 $1000 \mathrm{~mm}$ 时, 植被 $\delta^{13} \mathrm{C}$ 
与降水量也呈负相关. 非洲 $\mathrm{C}_{3}$ 植被 $\delta^{13} \mathrm{C}$ 分布表明离 海岸线较近的坦桑尼亚气候湿润, 植物组织的 $\delta^{13} \mathrm{C}$ 最负 ${ }^{[9]}$ (图 5); 南非比较干旱, $\mathrm{C}_{3}$ 植被的 $\delta^{13} \mathrm{C}$ 整体偏 正; 而埃塞俄比亚和肯尼亚两个区域与坦桑尼亚相 比较湿润, $\delta^{13} \mathrm{C}$ 处于干旱区和湿润区之间. 除水分条 件对植物碳同位素分馏的影响外，温度等的影响可 能会叠加在降水作用之上, 使其与 ${ }^{13} \mathrm{C}$ 的关系复杂 化. 在埃塞俄比亚, 植物生长的地理条件差异很大 (海拔在 930 4050 m 之间), 使得降水和温度对植物 碳同位素分馏的影响有所叠加; 而在非洲其他地区 的差异则相对较小. 非洲 $\mathrm{C}_{3}$ 植物的平均最大值和最 小值的差异为 $3.01 \%$ (图 5), 这种差异不仅有温度 ${ }^{[32]}$ 和降雨量 ${ }^{[1,31]}$ 的影响, 同时也包括植物所生长的环境 要素如土壤类型、地貌和海拔等对植物同位素分馏的 影响 ${ }^{[3]}$. 因此, 有必要对生长在不同环境下的植物的 碳氮同位素分馏过程和机理做进一步的研究.

\section{参考文献}

1 Street-Perrott F A, Huang Y, Perrott R A, et al. Carbon isotopes in lake sediments and peats of last glacial age: implications for the global carbon cycles. In: Griffiths H, ed. Stable isotopes: integration of biological, ecological and geochemical processes. Oxford: Bios Scientific Publishers, 1998. 381-392

2 Lamb A L, Melanie J L, Mohammed U M, et al. Holocene climate and vegetation change in the Main Ethiopian Rift Valley, inferred from the composition $\left(\mathrm{C} / \mathrm{N}\right.$ and $\left.\delta^{13} \mathrm{C}\right)$ of lacustrine organic matter. Quat Sci Rev, 2004, 23: 881-891

3 Heaton T H E. Spatial, species and temporal variations in the ${ }^{13} \mathrm{C} /{ }^{12} \mathrm{C}$ ratios of $\mathrm{C}_{3}$ plants: implications for palaeodiet studies. $\mathrm{J}$ Archaeol Sci, 1999, 26: 637-649

4 王建柱, 林光辉, 黄建辉, 等. 稳定同位素在陆地生态系统动植物相互关系研究中的应用. 科学通报, 2004, 49(21): 21412149

5 Farquhar G D, O'Leary M H, Berry J A. On the relationship between carbon isotope discrimination and the intercellular carbon dioxide concentration in leaves. Aust J Plant Physiol, 1982, 9: 121-137

6 O'Leary M H. Environmental effects on carbon isotope fractionation in terrestrial plants. In: Wada E, Yoneyama T, Minigawa M, et al. Stable Isotopes in the Biosphere. Kyoto: Kyoto University Press, 1995. 78-91

7 Farquhar G D, Ehleringer J R, Hubick K T. Carbon isotope discrimination and photosynthesis. Ann Rev Plant Physiol Mol Biol, 1989, 40: 503-537

8 Handley L L, Raven J A. The use of natural abundance of nitrogen isotopes in plant physiology and ecology. Plant Cell Environ, 1992, 15: $965-985$
9 Muzuka A N N. Isotopic composition of tropical East African flora and their potential as source indicators of organic matter in coastal marine sediments. J Afr Earth Sci, 1999, 28(3): 757-766

10 Robinson D. $\delta{ }^{15} \mathrm{~N}$ as an integrator of the nitrogen cycles. Trends Ecol Evol, 2001, 16: 153-162

11 Codron J, Codron D, Lee-Thorp J A, et al. Taxonomical, anatomical, and spatial-temporal variations in the stable carbon and nitrogen isotopic compositions of plants from an African savanna. J Archaeol Sci, 2005, 32: 1757-1772

12 Körner C H, Farquhar G D, Wong S C. Carbon isotope discrimination by plants follows latitudinal and altitudinal trends. Oecologia, 1991, 88: 30-40

13 Balesdent J, Girardin C, Mariotti A. Site related $\mathrm{d}^{13} \mathrm{C}$ of tree leaves and soil organic matter in a temperate forest. Ecology, 1993, 74: $1713-1721$

14 Marshall J D, Zhang J. Carbon isotope discrimination and water-use efficiency in native plants of the north-central Rockies. Ecology, 1994, 75: 1887-1895

15 Brooks J R, Flanagan L B, Buchmann N, et al. Carbon isotope composition of boreal plants: functional grouping of life forms. Oecologia, 1997, 110: 301-311

16 Schulze E D, Gebauer G, Ziegler H, et al. Estimates of nitrogen fixation by trees on an aridity gradient in Namibia. Oecologia, 1991, 88: 451-455

17 Handley L L, Odee D, Scrimgeour C M. $\delta{ }^{15} \mathrm{~N}$ and $\delta{ }^{13} \mathrm{C}$ patterns in savanna vegetation: dependence on water availability and disturbance. Funct Ecol, 1994, 8: 306-314

18 Zhang J, Marshall J D, Fins L. Correlated population differences in dry matter accumulation, allocation and water-use efficiency in three sympatric conifer species. For Sci, 1996, 42: 242-249

19 Nguyen-Queyrens A, Ferhi A, Loustau D, et al. Within-ring d13C spatial variability and inter-annual variations in wood cellulose of two contrasting provenances of Pinus pinaster. Can J For Res, 1998, 28: 766-773

20 Chorowicz J. The East African rift system. J Afr Earth Sci, 2005, 43(1-3): 379-410

21 Anon. National Atlas of Ethiopia. Ethiopian Mapping Authority, Addis Ababa, 1988

22 Eshetu Z, Högberg P. Effects of land use on ${ }^{15} \mathrm{~N}$ natural abundance of soils in Ethiopian highlands. Plant Soil, 2000, 222: 109-117

23 Teklay T, Malmer A. Decomposition of leaves from two indigenous trees of contrasting qualities under shaded-coffee and agricultural land-uses during the dry season at Wondo Genet, Ethiopia. Soil Bio Biochem, 2004, 36: 777-786

24 Lemenih M, Itanna F. Soil carbon stocks and turnovers in various vegetation types and arable lands along an elevation gradient in southern Ethiopia. Geoderma, 2004, 123: 177-188

25 Anon. Ethiopia. In: Meteorological Messages-List of Stations, A/9. Rome: WMO, 1982 
26 Abule E, Smit G N, Snyman H A. The influence of woody plants and livestock grazing on grass species composition, yield and soil nutrients in the Middle Awash Valley of Ethiopia. J Arid Environ, 2005, 60: $343-358$

27 Domenach A M, Kurdali F, Bardin R. Estimation of symbiotic dinitrogen fixation in alder forest by the method based on natural ${ }^{15} \mathrm{~N}$ abundance. Plant Soil, 1989, 118: 51-59

28 Schleser G H, Helle G, Lucke A, et al. Isotope signals as climate proxies: the role of transfer functions in the study of terrestrial archives. Quat Sci Rev, 1999, 18: 927-943

29 Leavitt S W, Long A. Evidence for ${ }^{13} \mathrm{C} /{ }^{12} \mathrm{C}$ fractionation between tree leaves and wood. Nature, 1982, 298: 742-743

30 Swap R J, Aranibar J N, Dowty P R, et al. Natural abundance of ${ }^{13} \mathrm{C}$ and ${ }^{15} \mathrm{~N}$ in $\mathrm{C}_{3}$ and $\mathrm{C}_{4}$ vegetation of southern Africa: patterns and implications. Glob Change Biol, 2004, 10: 350-358

31 王国安, 韩家惁, 刘东生. 中国北方黄土区 $\mathrm{C}_{3}$-草本植物稳定碳 同位素组成研究. 中国科学 D 辑: 地球科学, 2003, 33(6): 550556

32 王国安, 韩家禁, 周力平. 中国北方 $\mathrm{C}_{3}$ 植物碳同位素组成与年 均温度关系. 中国地质, 2002, 29(1): 55-57

33 Guo G M, Xie G D. The relationship between plant stable carbon isotope composition, precipitation and satellite data, Tibet Plateau, China. Quat Int, 2006, 144(1): 68-71

34 Qiang W Y, Wang X L, Chen T, et al. Variations of stomatal density and carbon isotope values of Picea crassifolia at different altitudes in the Qilian Mountains. Trees, 2003, 17: 258-262

35 旺罗, 吕厚远, 吴乃琴, 等. 青藏高原现生禾本科植物的 $\delta^{13} \mathrm{C}$ 与 海拔高度的关系. 第四纪研究, 2003, 23(5): 573-580

36 Hietz P, Wanek W, Popp M. Stable isotopic composition of carbon and nitrogen and nitrogen content in vascular epiphytes along an altitudinal transect. Plant Cell Environ, 1999, 22: 1435-1443

37 Kloeppel B D, Gower S T, Treichel I W, et al. Foliar carbon isotope discrimination in Larix species and sympatric evergreen conifers: a global comparison. Oecologia, 1988, 114: 153-159

38 Sparks J P, Ehleringer J R. Leaf carbon isotope discrimination and nitrogen content for riparian trees along elevational transects. Oecologia, 1997, 109: 362-367

39 Aranibar J N, Otter L, Macko S A, et al. Nitrogen cycling in the soil-plant system along a precipitation gradient in the Kalahari sands. Glob Change Biol, 2004, 10: 359-373

40 Koch P L, Behrensmeyer A K, Fogel M. The isotopic ecology of plants and animals in Amboseli National Park, Kenya. Geophysical Laboratory, Carnegie Institute Year Book 1990/1991, 1991, 163171

41 Linn D M, Doran J W. Effects of water-filled pore space on carbon dioxide and nitrous oxide production in tilled and nontilled soils. Soil Sci Soc Am J, 1984, 48: 1267-1272

42 Liu K, Kaplan I R. The eastern tropical Pacific as a source of ${ }^{15} \mathrm{~N}$-enrichment nitrate in seawater off southern California. Limnol Oceanogr, 1989, 34: 820-830

43 Heaton T H E. The ${ }^{15} \mathrm{~N} /{ }^{14} \mathrm{~N}$ ratios of plant in South Africa and Namibia: relationship to climate and coastal/saline environments. Oecologia, 1987, 74: 236-246

44 Handley L L, Austin A T, Robinson D, et al. The ${ }^{15} \mathrm{~N}$ natural abundance $\left(\delta^{15} \mathrm{~N}\right)$ of ecosystem samples reflects measure of water availability. Aust J Plant Physiol, 1999, 26: 185-199

45 Warren C R, McGrath J F, Adams M A. Water availability and carbon isotope discrimination in conifers. Oecologia, 2001, 127: 476 $-486$

46 Perman G I, Francey R J, Fraser P B. Climatic implications of stable isotope in tree rings. Nature, 1976, 260: 771-772

47 Raven J A, Farquhar G D. The influence of N metabolism and organic acid synthesis on the natural abundance of isotopes of carbon in plants. New Phytol, 1990, 116: 505-529 